\title{
The nutrition transition in Mexico 1988-2016: the role of wealth in the social patterning of obesity by education
}

\author{
Carolina Pérez-Ferrer ${ }^{1, *}$, Anne McMunn ${ }^{2}$, Paola Zaninotto ${ }^{2}$ and Eric J Brunner ${ }^{2}$
}

${ }^{1}$ Centro de Investigación en Salud Poblacional, Instituto Nacional de Salud Pública, 7a Cerrada de Fray Pedro de Gante 50, Tlalpan, Sección XVI, 14080 CDMX, Mexico City, Mexico: ${ }^{2}$ Research Department of Epidemiology and Public Health, University College London, London, UK

Submitted 3 November 2017: Final revision received 11 March 2018: Accepted 3 April 2018; First published online 10 May 2018

\begin{abstract}
Objective: The present study investigates whether the reversal of the social gradient in obesity, defined as a cross-over to higher obesity prevalence among groups with lower education level, has occurred among men and women in urban and rural areas of Mexico.

Design: Cross-sectional series of nationally representative surveys (1988, 1999, 2006, 2012 and 2016). The association between education and obesity was investigated over the period 1988-2016. Effect modification of the educationobesity association by household wealth was tested.

Setting: Mexico.

Subjects: Women ( $n$ 54816) and men ( $n$ 20 589) aged 20-49 years.

Results: In both urban and rural areas, the association between education and obesity in women varied by level of household wealth in the earlier surveys (1988, 1999 and 2006; interaction $P<0 \cdot 001)$. In urban areas in 1988, one level lower education was associated (prevalence ratio; 95\% CI) with 45\% higher obesity prevalence among the richest women $(1.45 ; 1.24,1.69)$, whereas among the poorest the same education difference was protective $(0.84 ; 0.72,0.99)$. In the latest surveys (2012, 2016), higher education was protective across all wealth groups. Among men, education level was not associated with obesity in urban areas; there was a direct association in rural areas. Wealth did not modify the association between education and obesity.

Conclusion: The reversal of the educational gradient in obesity among women occurred once a threshold level of household wealth was reached. Among men, there was no evidence of a reversal of the gradient. Policies must not lose sight of the populations most vulnerable to the obesogenic environment.
\end{abstract}

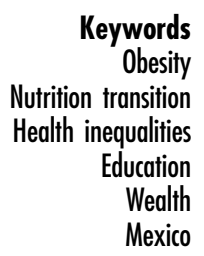

The social distribution of obesity is dynamic and changes as a function of country economic development and the nutrition transition ${ }^{(1-3)}$. In less developed countries obesity tends to be more prevalent among socially advantaged groups. As countries develop economically there tends to be a cross-over to higher rates of obesity among socially disadvantaged groups. This pattern of obesity prevalence, or reversal of the social gradient, may be explained by the process of the nutrition transition. In the early stages of the transition, food is scarce and not varied ${ }^{(4)}$. Socially disadvantaged populations are disproportionately affected and suffer from undernutrition. They are 'protected' from obesity by a lack of material resources and access to energy. As countries develop and economies become largely based on service industries, most can afford high-energy foods and avoid physical labour. As living conditions improve and food availability, accessibility and diversity increase, disadvantaged populations become at risk of obesity ${ }^{(5)}$. At the same time, more advantaged groups may become more health conscious and Western ideas of attractiveness associated with thinness may set in, which protects them from obesity.

The obesity prevalence among adults has more than trebled over a period of 25 years in Mexico ${ }^{(6)}$. It is unclear whether the social patterning of obesity over time in Mexico is consistent with the nutrition transition literature ${ }^{(2,7)}$. While there is evidence of an inverse association between education and obesity (lower education-higher obesity) among urban women since the late 1980s, there appears to be no association between education and obesity in rural areas and no evidence of a reversal of the social gradient ${ }^{(8)}$. 
Among men using data from 2000, no association between education and obesity was found ${ }^{(9)}$.

The aim of the present study was to investigate whether the reversal of the social (education) gradient in obesity has occurred or is due to occur among men and women in urban and rural areas of Mexico. At country level, gross national income is an effect modifier in the association between socio-economic position (SEP) and obesity ${ }^{(2,7)}$. Therefore, we hypothesize that within countries, household wealth will be an effect modifier in the association between education and obesity. Education will be protective of obesity over a certain level of household wealth and will not be protective within very poor households ${ }^{(5)}$. We use five waves of Mexican nationally representative data covering a period of 28 years over which there was sustained economic development and important changes in the food environment in the country ${ }^{(10)}$.

\section{Methodology}

\section{Data sources}

Data were extracted from five nationally representative cross-sectional surveys, in Spanish Encuesta Nacional de Nutrición (ENN) and Encuesta Nacional de Salud y Nutrición (ENSANUT), conducted in 1988, 1999, 2006, 2012 and $2016^{(11-15)}$. These surveys were designed to collect information on nutrition and the latter three on health and health-related services and interventions. The first two surveys focused on women aged $12-49$ years and children. The last three included men and women aged 20 years or above, children and adolescents. ENSANUT 2016 aimed to update key health and nutrition outcomes with a smaller sample compared with previous surveys. We selected women and men aged 20-49 years as our study population. Five data points were available for women $(1988,1999$, 2006, 2012 and 2016) and three for men (2006, 2012 and 2016). The design of the sample was similar in all surveys and included stratification and probabilistic selection of clusters in different stages. Individuals in the data sets carry a weight which represents the inverse probability of being sampled adjusted for survey non-response.

Response rates at household level ranged from 80 to $97 \%$. The achieved sample of households was in the range of 9479 in 2016 to 50528 in 2012. The total number of women aged 20-49 years with demographic information across the five surveys was 67071 . There were 30102 men aged 20-49 years with demographic information in the 2006, 2012 and 2016 surveys. Missing values for BMI were on average $17 \%$ across all surveys. Two of the data sets (1999 and 2006) did not distinguish between individuals who refused to be measured and those not selected to be measured. Therefore, missingness due to refusal to be measured is understood to be lower than the overall missingness level. Missing values for education and other covariates were all $<5 \%$. Cases with missing values were excluded after careful examination of missing data patterns suggested that selection bias in the main findings was minimal ${ }^{(16)}$. After exclusion of missing data and extreme implausible values for BMI (BMI $<10 \mathrm{~kg} / \mathrm{m}^{2}$, BMI $>75 \mathrm{~kg} / \mathrm{m}^{2}$; less than $0.5 \%$ of the total sample), our analytical sample consisted of 54816 non-pregnant women and 20589 men aged $20-49$ years.

\section{Outcome, exposure and covariates}

BMI was calculated as weight (in kilograms) divided by the square of height (in metres). Obesity was defined as a BMI $\geq 30 \mathrm{~kg} / \mathrm{m}^{2}$. Height and weight were measured using standard procedures by trained health teams during home visits $^{(11-13,17)}$. The main exposure variable was achieved level of education and was categorized as high school or more, secondary, primary and incomplete primary. These categories refer to well-known milestones in the Mexican education system. Education is understood as a measure of adult SEP and likely associated with health by making people more receptive to health education messages and more prone to healthier behaviours.

A wealth index was constructed as a measure of material resources $^{(18)}$. The index was constructed in each survey using relevant household quality and asset variables (see online supplementary material 1, Tables S1-S3, for more details). Asset ownership and household quality characteristics are likely based at least partially on economic wealth and unlikely to change in response to short-term economic shocks. Relevant variables were those that had the potential to discriminate between wealth groups. If mean ownership of the asset was high (above $85 \%$ ), the variable was not selected. Principal component analysis was used to replace the set of correlated assets and household quality variables with a set of uncorrelated principal components which represent unobserved characteristics of the population ${ }^{(19)}$. The first principal component was kept as it captured the most covariance ( $40 \%$ on average across surveys). The weights for each variable from the first component were used to generate a household score. The relative rank of households using this score was used as a measure of relative wealth ${ }^{(18,19)}$. Tertiles of the score were created for each survey individually. The wealth index had internal coherence, such that there were large differences in ownership of assets between wealth groups (see supplementary material 1).

A linear term and a quadratic term of age were included as adjustment covariates in all models because there was a statistically significant curvilinear association between age and obesity prevalence in all survey years. Area of residence has been identified as an effect modifier of the association between education and obesity in previous studies $^{(20)}$, thus analyses were stratified by this variable. Urban areas were defined in the surveys as communities with more than 2500 inhabitants and rural areas as those with fewer than 2500 inhabitants. 


\section{Statistical analysis}

All analyses accounted for the complex survey design and were weighted. Weights in these surveys represent the inverse probability of being sampled adjusted for survey non-response. Age-standardized obesity prevalence by education group was computed using the Mexican 2000 census population as the standard population. The association between education and obesity was assessed in a regression model where the outcome was obesity and the exposure was education as a continuous variable, adjusted for age and age-squared ${ }^{(21,22)}$. Generalized linear models ( $\log$ binomial regression) were used instead of logistic regression as has been recommended when modelling frequent outcomes ${ }^{(21,22)}$. Generalized linear models estimate the prevalence ratio.

To test whether wealth modifies the association between education and obesity, the regression of obesity $v$. the continuous education variable was performed within each wealth tertile. An interaction term between education and wealth was fitted in a separate model. The interaction term was examined for statistical significance using a Wald test. This methodology was repeated for each survey year for urban and rural areas, men and women. The two more recent surveys (2012 and 2016) were pooled since the 2016 sample was small and when divided into several strata the number for each cell was too small for analyses. For the same reason, 1988 and 1999 were pooled for women in rural areas.

\section{Results}

The correlation of education and wealth was low to moderate, ranging from 0.38 to 0.48 in urban areas and from 0.21 to 0.48 in rural areas for women and from 0.37 to 0.43 and 0.24 to 0.31 in urban and rural areas, respectively, for men. The rural population made up on average $21 \%$ of the total population throughout the period. Table 1 shows the characteristics of the study population. There were improvements in education over the 28-year period for women and over the 10-year period for men. The proportion of women with complete high school more than doubled from 1988 to 2016 (from 15.3 to $38.7 \%$ ) in urban areas and quadrupled in rural areas (from 5.0 to $20.5 \%$ ), while the proportion with incomplete primary education declined from 33.9 to $6.6 \%$ in urban areas and from 61.7 to $18.7 \%$ in rural areas. Men achieved a higher level of education than women in urban areas but not in rural areas. In terms of wealth, the largest proportion of urban households were classified in the richest tertile, while the largest proportion of households in rural areas belonged to the poorest tertile.

Obesity prevalence continued to increase, especially among women, reaching $37 \cdot 1 \%$ in urban areas and $35.7 \%$ in rural areas in 2016 (Table 1). Among men, obesity prevalence was higher in urban areas compared with rural areas throughout the study period. Table 2 shows obesity prevalence stratified by education level for men and women in urban and rural areas. Education was inversely associated with obesity prevalence (lower education levelhigher obesity prevalence) among urban women throughout the study period. Obesity prevalence reached $49.9 \%$ among women with incomplete primary education in 2016 compared with $31.5 \%$ among women with high school or more. In rural areas, education was not associated with obesity prevalence (Table 2). Among men there was a direct association (lower education level-lower obesity prevalence) between education and obesity prevalence in rural areas and no association in urban areas.

Table 3 shows the association between education and obesity prevalence stratified by wealth tertiles. In 1988 among the richest tertile of urban women, one level lower education was associated with $45 \%$ higher obesity prevalence (prevalence ratio $=1.45 ; 95 \%$ CI 1.24, 1.69), while among the poorest tertile one level lower education was protective of obesity (prevalence ratio $=0.84 ; 95 \% \mathrm{CI}$ $0.72,0.99$ ). The association between education and obesity prevalence varied by level of wealth (interaction $P<0 \cdot 001$ ). The same pattern was seen among urban women in 1999 and among rural women in 1988/1999 and 2006. As of 2006, the association between education and obesity prevalence did not vary by level of wealth. In online supplementary material 2, Figs S1-S11 illustrate the interaction in the different survey years. Among men, the association between education and obesity did not vary by level of wealth.

\section{Discussion}

In the present study we examined the social distribution of obesity in Mexico in greater detail than previous studies by using data from five nationally representative surveys covering a period of 28 years, including men and women, and using two dimensions of SEP: education and wealth. Our study found that obesity prevalence continued to increase among all education groups in men and women, urban and rural areas of Mexico from 2012 to 2016. The association between education and obesity was modified by wealth among women in the earlier surveys in 1988 , 1999 and 2006; while among the richer tertiles, education was protective of obesity prevalence, among the poorest tertile, education was not associated with obesity prevalence or appeared to be a risk factor. This interaction was no longer significant in the more recent surveys, suggesting a reversal of the educational gradient among the poorest women. Among men, the association between education and obesity was not modified by wealth. In urban areas, education was not associated with obesity regardless of wealth and in rural areas, there was a direct association between education and obesity. Our results contribute to the evidence supporting the nutrition transition proposition of a reversal of the social gradient in 
Table 1 Descriptive characteristics of Mexican men ( $n$ 20 589) and women ( $n$ 54 816) aged $20-49$ years in urban and rural areas; data from five nationally representative cross-sectional surveys, Encuesta Nacional de Nutrición (ENN) and Encuesta Nacional de Salud y Nutrición (ENSANUT), conducted in 1988, 1999, 2006, 2012 and 2016

\begin{tabular}{|c|c|c|c|c|c|c|c|c|c|c|c|c|c|c|c|c|}
\hline & \multicolumn{10}{|c|}{ Women } & \multicolumn{6}{|c|}{ Men } \\
\hline & \multicolumn{2}{|c|}{1988} & \multicolumn{2}{|c|}{1999} & \multicolumn{2}{|c|}{2006} & \multicolumn{2}{|c|}{2012} & \multicolumn{2}{|c|}{2016} & \multicolumn{2}{|c|}{2006} & \multicolumn{2}{|c|}{2012} & \multicolumn{2}{|c|}{2016} \\
\hline & $\begin{array}{c}\text { Mean or } \\
\%\end{array}$ & SE & $\begin{array}{c}\text { Mean o } \\
\%\end{array}$ & SE & $\begin{array}{c}\text { Mean o } \\
\%\end{array}$ & SE & $\begin{array}{c}\text { Mean o } \\
\%\end{array}$ & SE & $\begin{array}{c}\text { Mean o } \\
\%\end{array}$ & SE & $\begin{array}{c}\text { Mean o } \\
\%\end{array}$ & SE & $\underset{\%}{\text { Mean }} \mathrm{O}$ & SE & $\begin{array}{c}\text { Mean or } \\
\%\end{array}$ & SE \\
\hline \multicolumn{17}{|l|}{ Urban } \\
\hline$n$ & \multicolumn{2}{|c|}{8995} & \multicolumn{2}{|c|}{8228} & \multicolumn{2}{|c|}{9906} & \multicolumn{2}{|c|}{9588} & \multicolumn{2}{|c|}{1724} & \multicolumn{2}{|c|}{6513} & \multicolumn{2}{|c|}{6734} & \multicolumn{2}{|l|}{748} \\
\hline Mean age (years) & $32 \cdot 4$ & 0.1 & $32 \cdot 8$ & 0.1 & 34.0 & 0.1 & 33.8 & 0.1 & $33 \cdot 6$ & 0.3 & $33 \cdot 3$ & 0.2 & 33.2 & 0.2 & $32 \cdot 8$ & 0.4 \\
\hline $\begin{array}{l}\text { Obesity } \\
\text { prevalence* }\end{array}$ & 9.5 & 0.4 & $25 \cdot 8$ & 0.5 & $30 \cdot 9$ & 0.7 & 34.5 & 0.8 & $37 \cdot 1$ & $2 \cdot 0$ & $23 \cdot 9$ & 0.8 & $29 \cdot 5$ & 0.8 & $30 \cdot 7$ & $2 \cdot 6$ \\
\hline \multicolumn{17}{|l|}{ Education } \\
\hline$\geq$ High school & $15 \cdot 3$ & 0.8 & 34.3 & 0.8 & $26 \cdot 5$ & 0.9 & 38.0 & 0.9 & 38.7 & 3.2 & $35 \cdot 3$ & 0.9 & $40 \cdot 6$ & 0.9 & 44.3 & $3 \cdot 1$ \\
\hline Secondary & $22 \cdot 0$ & 0.7 & $21 \cdot 7$ & 0.5 & $32 \cdot 2$ & 0.8 & $32 \cdot 8$ & 0.8 & $38 \cdot 6$ & $2 \cdot 3$ & $32 \cdot 6$ & 0.9 & 33.3 & 0.9 & 34.7 & $2 \cdot 9$ \\
\hline Primary & 28.8 & 0.7 & 24.5 & 0.5 & 24.2 & 0.7 & 18.6 & 0.6 & $16 \cdot 1$ & 1.6 & $20 \cdot 8$ & 0.7 & $17 \cdot 8$ & 0.7 & 14.9 & 1.8 \\
\hline$<$ Primary & 33.9 & $1 \cdot 3$ & $19 \cdot 5$ & 0.7 & $17 \cdot 0$ & 0.7 & $10 \cdot 6$ & 0.5 & $6 \cdot 6$ & 0.8 & $11 \cdot 3$ & 0.5 & $8 \cdot 3$ & 0.4 & $6 \cdot 1$ & $1 \cdot 1$ \\
\hline \multicolumn{17}{|l|}{ Wealth } \\
\hline Richest & $36 \cdot 4$ & 1.5 & $50 \cdot 8$ & 0.9 & $45 \cdot 7$ & 1.0 & $47 \cdot 7$ & 1.1 & 58.4 & $2 \cdot 8$ & 47.9 & 0.9 & $49 \cdot 7$ & 0.9 & 60.4 & 2.9 \\
\hline Middle & $29 \cdot 1$ & 1.0 & $35 \cdot 0$ & 0.7 & 34.7 & 0.8 & 33.7 & 0.8 & $25 \cdot 8$ & $2 \cdot 1$ & $34 \cdot 6$ & 0.9 & 33.8 & 0.9 & $25 \cdot 9$ & $2 \cdot 7$ \\
\hline Poorest & 34.5 & $1 \cdot 7$ & $14 \cdot 2$ & 0.6 & $19 \cdot 6$ & 0.8 & $18 \cdot 6$ & 0.8 & $15 \cdot 8$ & 1.7 & $17 \cdot 5$ & 0.6 & $16 \cdot 6$ & 0.6 & $13 \cdot 7$ & $1 \cdot 6$ \\
\hline \multicolumn{17}{|l|}{ Rural } \\
\hline$n$ & \multicolumn{2}{|c|}{1323} & \multicolumn{2}{|c|}{4312} & \multicolumn{2}{|c|}{4068} & \multicolumn{2}{|c|}{4943} & 172 & & 234 & & 339 & & 853 & \\
\hline Mean age (years) & $32 \cdot 2$ & 0.3 & $32 \cdot 6$ & 0.1 & 33.7 & 0.2 & 33.4 & 0.2 & 33.2 & 0.4 & 34.9 & 0.2 & 33.3 & 0.2 & 33.2 & 0.5 \\
\hline $\begin{array}{l}\text { Obesity } \\
\text { prevalence* }\end{array}$ & $8 \cdot 1$ & $1 \cdot 2$ & 21.5 & 0.8 & $27 \cdot 9$ & $1 \cdot 2$ & $30 \cdot 7$ & 1.0 & $35 \cdot 7$ & $2 \cdot 0$ & $17 \cdot 5$ & $1 \cdot 1$ & $20 \cdot 3$ & 1.0 & $22 \cdot 6$ & 1.9 \\
\hline Education & & & & & & & & & & & & & & & & \\
\hline$\geq$ High school & $5 \cdot 0$ & 1.0 & $7 \cdot 1$ & 0.7 & $5 \cdot 6$ & 0.6 & $16 \cdot 0$ & 1.0 & $20 \cdot 5$ & $1 \cdot 8$ & 7.9 & 0.8 & $17 \cdot 9$ & 1.0 & $15 \cdot 9$ & 1.8 \\
\hline Secondary & $11 \cdot 2$ & $1 \cdot 7$ & $12 \cdot 1$ & 0.7 & $21 \cdot 0$ & $1 \cdot 1$ & $30 \cdot 8$ & 1.3 & $37 \cdot 3$ & 2.4 & 22.5 & 1.2 & $30 \cdot 1$ & 1.1 & 38.8 & 3.0 \\
\hline Primary & $22 \cdot 1$ & $2 \cdot 3$ & $28 \cdot 1$ & 0.9 & 29.5 & $1 . .0$ & $28 \cdot 0$ & 1.0 & 23.5 & 1.5 & 32.5 & 1.3 & $28 \cdot 6$ & $1 \cdot 1$ & $26 \cdot 4$ & $2 \cdot 8$ \\
\hline$<$ Primary & $61 \cdot 7$ & $4 \cdot 1$ & $52 \cdot 7$ & 1.4 & 43.9 & $1 \cdot 6$ & $25 \cdot 2$ & $1 \cdot 2$ & $18 \cdot 7$ & $2 \cdot 5$ & $37 \cdot 1$ & 1.4 & 23.5 & 1.0 & $18 \cdot 9$ & $2 \cdot 3$ \\
\hline Wealth & & & & & & & & & & & & & & & & \\
\hline Richest & $10 \cdot 6$ & $2 \cdot 1$ & $8 \cdot 3$ & 0.7 & 8.0 & 0.9 & $15 \cdot 3$ & 1.0 & $23 \cdot 2$ & $2 \cdot 7$ & 9.7 & 1.0 & $15 \cdot 8$ & 0.9 & $19 \cdot 2$ & $2 \cdot 3$ \\
\hline Middle & 19.5 & $2 \cdot 7$ & $29 \cdot 1$ & $1 \cdot 3$ & $26 \cdot 3$ & 1.4 & 33.6 & $1 \cdot 2$ & $35 \cdot 7$ & $2 \cdot 0$ & $27 \cdot 8$ & 1.3 & $32 \cdot 6$ & 1.1 & 35.9 & 3.0 \\
\hline Poorest & 69.9 & 4.4 & $62 \cdot 6$ & $1 \cdot 7$ & $65 \cdot 6$ & $1 \cdot 8$ & $51 \cdot 1$ & 1.6 & $41 \cdot 1$ & 3.4 & $62 \cdot 5$ & 1.4 & $51 \cdot 6$ & $1 \cdot 1$ & $44 \cdot 9$ & 3.0 \\
\hline
\end{tabular}

Data are presented as percentages with their standard errors except for $n$ and age; age is presented as means with their standard errors.

${ }^{*}$ Age-standardized obesity prevalence.

Table 2 Distribution of age-standardized obesity prevalence by education level among Mexican men ( $n 20589)$ and women $(n 54816)$ aged 20-49 years in urban and rural areas; data from five nationally representative cross-sectional surveys, Encuesta Nacional de Nutrición (ENN) and Encuesta Nacional de Salud y Nutrición (ENSANUT), conducted in 1988, 1999, 2006, 2012 and 2016

\begin{tabular}{|c|c|c|c|c|c|c|c|c|c|c|c|c|c|c|c|c|}
\hline & \multicolumn{10}{|c|}{ Women } & \multicolumn{6}{|c|}{ Men } \\
\hline & \multicolumn{2}{|c|}{1988} & \multicolumn{2}{|c|}{1999} & \multicolumn{2}{|c|}{2006} & \multicolumn{2}{|c|}{2012} & \multicolumn{2}{|c|}{2016} & \multicolumn{2}{|c|}{2006} & \multicolumn{2}{|c|}{2012} & \multicolumn{2}{|c|}{2016} \\
\hline & $\%$ & SE & $\%$ & SE & $\%$ & SE & $\%$ & SE & $\%$ & SE & $\%$ & SE & $\%$ & SE & $\%$ & SE \\
\hline \multicolumn{17}{|l|}{ Urban } \\
\hline$\geq$ High school & $5 \cdot 1$ & 0.9 & $20 \cdot 0$ & 0.9 & $23 \cdot 6$ & 1.4 & $29 \cdot 3$ & $1 \cdot 2$ & 31.5 & 3.5 & 24.5 & 1.4 & $30 \cdot 9$ & $1 \cdot 3$ & $36 \cdot 8$ & 4.5 \\
\hline Secondary & $7 \cdot 7$ & 0.9 & $24 \cdot 2$ & $1 \cdot 1$ & $30 \cdot 4$ & $1 \cdot 2$ & $36 \cdot 2$ & $1 \cdot 3$ & $38 \cdot 3$ & $3 \cdot 1$ & 23.0 & 1.4 & $29 \cdot 3$ & 1.5 & 20.5 & $2 \cdot 8$ \\
\hline Primary & 11.7 & 0.7 & $27 \cdot 7$ & 1.0 & 35.5 & 1.5 & 38.8 & 1.8 & 39.4 & 4.0 & $25 \cdot 8$ & 1.7 & 30.6 & $2 \cdot 0$ & 32.4 & 5.4 \\
\hline$<$ Primary & $10 \cdot 2$ & 0.7 & 33.6 & 1.4 & $37 \cdot 8$ & 1.9 & $37 \cdot 0$ & $2 \cdot 5$ & $49 \cdot 9$ & $6 \cdot 8$ & 19.5 & $1 \cdot 8$ & 23.5 & $2 \cdot 2$ & $39 \cdot 1$ & 8.0 \\
\hline \multicolumn{17}{|l|}{ Linear trend } \\
\hline PR & \multirow{2}{*}{\multicolumn{2}{|c|}{$\begin{array}{c}1 \cdot 20 \\
1 \cdot 10,1 \cdot 32\end{array}$}} & \multirow{2}{*}{\multicolumn{2}{|c|}{$\begin{array}{c}1 \cdot 18 \\
1 \cdot 14,1 \cdot 23\end{array}$}} & \multirow{2}{*}{\multicolumn{2}{|c|}{$\begin{array}{c}1 \cdot 15 \\
1 \cdot 11,1 \cdot 19\end{array}$}} & \multirow{2}{*}{\multicolumn{2}{|c|}{$\begin{array}{c}1 \cdot 11 \\
1.07,1 \cdot 15\end{array}$}} & \multirow{2}{*}{\multicolumn{2}{|c|}{$\begin{array}{c}1 \cdot 16 \\
1.05,1 \cdot 28\end{array}$}} & \multirow{2}{*}{\multicolumn{2}{|c|}{$\begin{array}{c}0.97 \\
0.91,1.03\end{array}$}} & \multirow{2}{*}{\multicolumn{2}{|c|}{$\begin{array}{c}0.96 \\
0.91,1.01\end{array}$}} & \multirow{2}{*}{\multicolumn{2}{|c|}{$\begin{array}{c}0.91 \\
0.72,1.13\end{array}$}} \\
\hline $95 \% \mathrm{Cl}$ & & & & & & & & & & & & & & & & \\
\hline \multicolumn{17}{|l|}{ Rural } \\
\hline$\geq$ High school & $2 \cdot 8$ & 1.5 & $18 \cdot 2$ & $2 \cdot 2$ & $26 \cdot 2$ & $4 \cdot 3$ & $24 \cdot 3$ & $2 \cdot 1$ & $26 \cdot 5$ & 4.4 & $24 \cdot 7$ & 4.4 & $25 \cdot 5$ & $2 \cdot 6$ & $32 \cdot 0$ & $4 \cdot 3$ \\
\hline Secondary & 8.2 & $2 \cdot 7$ & 28.7 & $2 \cdot 3$ & $29 \cdot 0$ & $2 \cdot 5$ & $32 \cdot 1$ & 1.7 & 39.2 & 3.0 & $20 \cdot 0$ & $2 \cdot 4$ & 21.9 & 1.6 & $26 \cdot 4$ & 3.5 \\
\hline Primary & $10 \cdot 3$ & $2 \cdot 4$ & $26 \cdot 6$ & 1.5 & $30 \cdot 6$ & $1 \cdot 8$ & $31 \cdot 8$ & $2 \cdot 0$ & $42 \cdot 2$ & $4 \cdot 3$ & $17 \cdot 6$ & $1 \cdot 8$ & $20 \cdot 8$ & 1.9 & $20 \cdot 0$ & 3.4 \\
\hline$<$ Primary & 7.5 & $1 \cdot 3$ & $19 \cdot 8$ & 1.0 & $27 \cdot 1$ & $2 \cdot 3$ & 31.6 & $2 \cdot 2$ & $37 \cdot 0$ & $5 \cdot 7$ & 14.4 & 1.6 & $15 \cdot 2$ & $2 \cdot 3$ & $16 \cdot 5$ & 3.8 \\
\hline \multicolumn{17}{|l|}{ Linear trend } \\
\hline PR & \multirow{2}{*}{\multicolumn{2}{|c|}{$\begin{array}{c}0.99 \\
0.79,1.24\end{array}$}} & \multirow{2}{*}{\multicolumn{2}{|c|}{$\begin{array}{c}0.93 \\
0.87,0.98\end{array}$}} & \multirow{2}{*}{\multicolumn{2}{|c|}{$\begin{array}{c}0.94 \\
0.87,1.03\end{array}$}} & \multirow{2}{*}{\multicolumn{2}{|c|}{$\begin{array}{c}1.02 \\
0.97,1.09\end{array}$}} & \multirow{2}{*}{\multicolumn{2}{|c|}{$\begin{array}{c}1.02 \\
0.91,1.15\end{array}$}} & \multirow{2}{*}{\multicolumn{2}{|c|}{$\begin{array}{c}0.88 \\
0.78,1.00\end{array}$}} & \multirow{2}{*}{\multicolumn{2}{|c|}{$\begin{array}{c}0.86 \\
0.78,0.94\end{array}$}} & \multirow{2}{*}{\multicolumn{2}{|c|}{$\begin{array}{c}0.77 \\
0.64,0.93\end{array}$}} \\
\hline $95 \% \mathrm{Cl}$ & & & & & & & & & & & & & & & & \\
\hline
\end{tabular}

PR, prevalence ratio. 


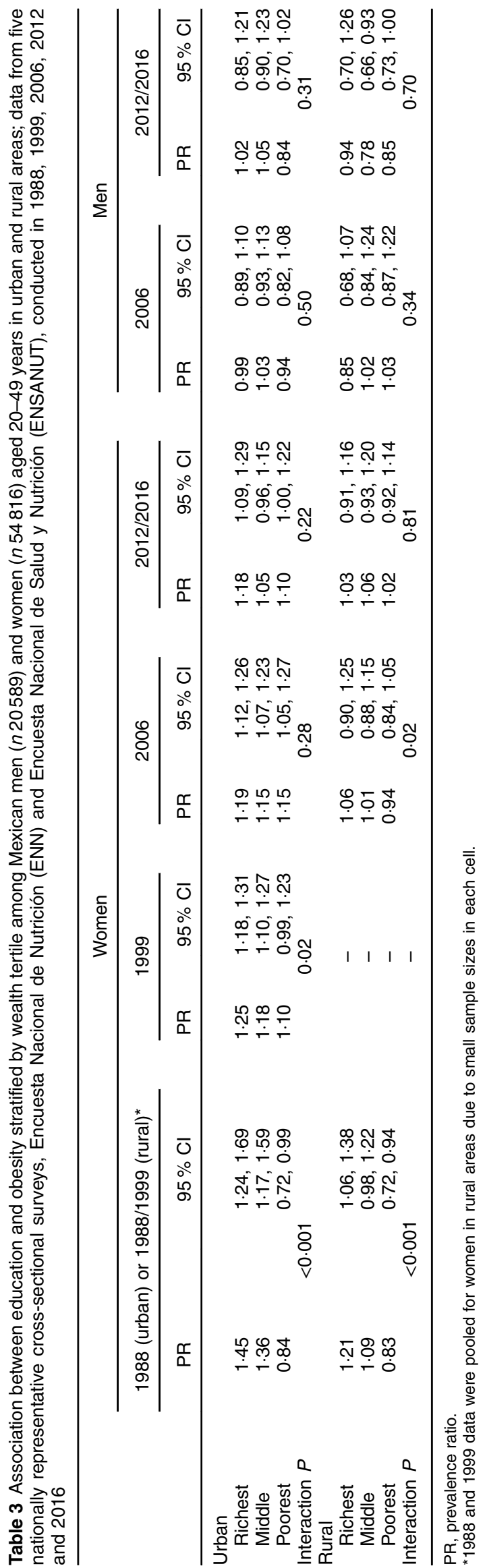

obesity as countries develop but only among women. They challenge this proposition for men ${ }^{(2)}$.

Our hypothesis, that household wealth would be an effect modifier in the association between education and obesity, was supported among women. In the earlier surveys, when absolute poverty was more widespread, wealth was an effect modifier of the association between education and obesity. Education was protective among the relatively richer groups but not among the poorest. The poorest groups were poor in absolute terms that may have meant limited access to foods and high physical activity associated with manual occupations, which 'protected' them from obesity. In the more recent surveys as the country has continued to develop economically, the relatively poorest women have crossed the wealth threshold, which we interpret as women becoming vulnerable to the obesogenic environment. In this situation, education becomes protective for the poor as well as for richer women.

These findings are consistent with Mexican studies conducted among low-income populations ${ }^{(23,24)}$. Fernald et al. reported that education was directly associated with obesity among women living in poor communities in 2003. Our study gives context to Fernald et al.'s findings which seemed at odds with contemporaneous Mexican studies using nationally representative data that had found an inverse association between education and obesity. Further, our findings may also explain why no association between education and obesity had been reported in rural areas $^{(8,9)}$ even at levels of gross national income per capita above \$US 8000 (significantly above the wealth threshold for the reversal of the social gradient in countries ${ }^{(2)}$ ). High income inequality has persisted in Mexico, so it is plausible that a large proportion of the rural population was and is still living in extreme poverty; that is, below the wealth threshold at which they would become at risk of obesity.

Education may affect health directly by affecting a person's receptivity to health education messages and making him or her more prone to healthier behaviours ${ }^{(25)}$. Education may also be associated with health indirectly by affecting employment prospects, types of occupation and income ${ }^{(26)}$. Income has been associated with obesity through its conversion into health-enhancing commodities through expenditure ${ }^{(25)}$. In developed countries, higher income is associated with consumption of healthier more expensive foods ${ }^{(27)}$.

Among men our hypothesis was not supported; there was no evidence of a cross-over to higher prevalence of obesity among less educated men. The literature suggests that the strength of the association between SEP and obesity is weaker for men ${ }^{(1,2)}$ and the country wealth threshold at which the reversal of the social gradient occurs is higher compared with women ${ }^{(2,28)}$. The absence to date of a cross-over to higher rates of obesity among disadvantaged men is not consistent with the social 
determinants of health model, which suggests that, in general, lower SEP is linked with adverse health status ${ }^{(29)}$. Usually in more developed countries, disadvantage is associated with adverse living conditions, psychosocial risk factors and unhealthy behaviours which lead to an increased risk of diseases. The social distribution of obesity among men in Mexico, and potentially other similarly developed countries, may be to do with higher physical activity being associated with social disadvantage and thus protecting disadvantaged groups from obesity. Manual jobs such as agriculture in rural areas and building and construction in urban areas are associated with lower education and lower obesity prevalence.

There are policy implications from the present study. First, we have documented a further increase in obesity prevalence among both men and women in the most recent years (2012-2016), with dramatic increases in obesity prevalence among women with less than primary education. This shows that the policies and programmes implemented so far in Mexico, particularly the tax on sugar-sweetened beverages and widespread health promotion campaigns, have not been enough to curb the upward trends. Additional policies and programmes are urgently needed which must take account of the social distribution of obesity prevalence. Both population-wide and targeted interventions to the most vulnerable are needed to address increasing health inequalities. Second, although education is protective of obesity as shown in our study, improving education is insufficient to reverse the increase in obesity prevalence. We have shown large improvements in education over the period 1988 to 2016 and large increases in obesity prevalence. Individual protective factors such as education seem to be eclipsed by obesogenic changes in the food environment. More action on regulating the food environment, including food labelling, food prices, product formulation and marketing, is needed.

\section{Strengths and limitations of the study}

Our study strengths include using nationally representative data from comparable health surveys over a period of 28 years for women and 10 years for men. The length of the period and quality of the Mexican surveys, uncommon in low- and middle-income countries, allowed for the current detailed analysis of the social distribution of obesity which significantly develops the literature on the topic. Trained personnel measured height and weight. Two dimensions of SEP were used, education and wealth, with a clear theoretical underpinning. Our study showed that wealth and education measure different aspects of SEP and were only moderately correlated, potentially due to lower monetary rewards for educational investments in markets that are not fully developed like Mexico's ${ }^{(7)}$. The low correlation allowed for the study's robust analyses.
Education level is minimally prone to recall bias and is frequently used as an indicator of SEP in low- and middleincome countries; its use allows comparability with previous studies. The wealth index was constructed for the present study using a unified methodology across surveys. Assets and household characteristics were carefully selected based on a priori criteria. The index was robust in discriminating across wealth groups as shown in supplementary material 1 . In Mexico, the wealth index may provide a more stable and reliable measure of material resources than consumption expenditure since consumption expenditure may be volatile and inaccurate due to economic shocks and seasonality in consumption patterns ${ }^{(30)}$.

The surveys were cross-sectional and therefore have the expected limitations. Exposure, effect modifier and outcome variables were measured at the same point in time. Temporality cannot be established and therefore reverse causality in the associations observed cannot be rejected. However, reverse causality in the association between education and obesity is unlikely. Education is completed in the early years of adulthood while obesity prevalence increases with age ${ }^{(16)}$.

The meaning of education may vary for different cohorts with differing distributions of knowledge, skills and opportunities that affect health ${ }^{(25)}$. We believe this is unlikely to have affected our findings since a previous study using Mexican data suggested that the protective effect of education was not significantly different for women born earlier in the century (less educated) than later (more educated) ${ }^{(8)}$. A further limitation of education in the present study is that it was not possible to distinguish between good- and poor-quality education with the available data sets. The quality of education is likely to influence knowledge, cognitive skills and analytical abilities in the health domain ${ }^{(25)}$.

The wealth index measured relative wealth in each survey, but absolute levels of wealth were potentially higher with each subsequent survey. A sensitivity analysis using a wealth index constructed from the same assets and household characteristics across surveys showed similar results (data not shown). It was felt that using surveyspecific variables made the index more robust ${ }^{(16)}$. Related to this point, the wealth threshold referred to herein cannot be specified in monetary or income terms because of its relative nature.

\section{Conclusion}

Obesity prevalence in Mexico continued to increase among all socio-economic groups but the highest burden was among the most disadvantaged women, where almost one in two was obese in 2016. The study showed that upon reaching a threshold level of household wealth, the relatively poorest women became vulnerable to the 
obesogenic environment. A full reversal of the education gradient is expected among women in rural areas. Among men, obesity prevalence increased over the study period but was not socially patterned by education in urban areas and there was no evidence to suggest emerging inequalities in obesity. In rural areas, there was a direct association between education and obesity among men. These findings underscore the importance of current efforts in public policy to curb the obesity epidemic in Mexico ${ }^{(31)}$ and suggest that more effort is needed to reverse the trends. The findings also identify the most vulnerable groups. Policy makers must keep in mind health inequalities as they design and implement future policies and programmes.

\section{Acknowledgements}

Financial support: C.P.-F. was funded by a PhD scholarship (grant number 309252) from the Mexican Council for Science and Technology (CONACYT). CONACYT had no role in the design, analysis or writing of this article. Conflict of interest: None. Authorship: C.-P.F., A.M. and E.J.B. conceived of and designed the study. C.P.-F. analysed the data. C.P.-F., A.M., P.Z. and E.J.B. interpreted the findings. C.P.-F., A.M., P.Z. and E.J.B. wrote the paper. Ethics of buman subject participation: Written consent was obtained from adults participating in the surveys. The study protocol, data collection instruments, consent forms and procedures were approved by the ethics committee of the National Institute of Public Health in Mexico. The present study was based on anonymous, public-use data sets with no identifiable information on the study participants.

\section{Supplementary material}

To view supplementary material for this article, please visit https://doi.org/10.1017/S1368980018001167

\section{References}

1. McLaren L (2007) Socioeconomic status and obesity. Epidemiol Rev 29, 29-48.

2. Monteiro CA, Moura EC, Conde WL et al. (2004) Socioeconomic status and obesity in adult populations of developing countries: a review. Bull World Health Organ 82, 940-946.

3. Sobal J \& Stunkard AJ (1989) Socioeconomic status and obesity: a review of the literature. Psychol Bull 105, 260-275.

4. Popkin BM (1994) The nutrition transition in low-income countries: an emerging crisis. Nutr Rev 52, 285-298.

5. Levasseur P (2015) Causal effects of socioeconomic status on central adiposity risks: evidence using panel data from urban Mexico. Soc Sci Med 136-137, 165-174.

6. Barquera S, Campos-Nonato I, Hernandez-Barrera L et al. (2009) Obesity and central adiposity in Mexican adults: results from the Mexican National Health and Nutrition Survey 2006. Salud Publica Mex 51, Suppl. 4, S595-S603.
7. Dinsa GD, Goryakin Y, Fumagalli E et al. (2012) Obesity and socioeconomic status in developing countries: a systematic review. Obes Rev 13, 1067-1079.

8. Perez Ferrer C, McMunn A, Rivera Dommarco JA et al. (2014) Educational inequalities in obesity among Mexican women: time-trends from 1988 to 2012. PLoS One 9, e90195.

9. Buttenheim AM, Wong R, Goldman N et al. (2010) Does social status predict adult smoking and obesity? Results from the 2000 Mexican National Health Survey. Glob Public Health 5, 413-426.

10. Rivera JA, Barquera S, Gonzalez-Cossio T et al. (2004) Nutrition transition in Mexico and in other Latin American countries. Nutr Rev 62, 7 Pt 2, S149-S157.

11. Resano-Perez E, Mendez-Ramirez I, Shamah-Levy T et al. (2003) Methods of the national nutrition survey 1999. Salud Publica Mex 45, Suppl. 4, S558-S564.

12. Sepulveda J, Lezana MA, Tapia-Conyer R et al. (1990) Estado nutricional de preescolares y mujeres en Mexico: resultados de una encuesta probabilistica nacional. Gac Med Mex 126, 207-224.

13. Olaiz G, Rivera J, Shamah-Levy T et al. (2006) Encuesta Nacional de Salud y Nutricion 2006. Cuernavaca, Mexico: Instituto Nacional de Salud Publica.

14. Romero-Martínez M, Shamah-Levy T, Franco-Núñez A et al. (2013) Encuesta Nacional de Salud y Nutrición 2012: diseño y cobertura. Salud Publica Mex 55, Suppl. 2, S332-S340.

15. Instituto Nacional de Salud Publica (2017) Encuesta Nacional de Salud y Nutrición 2016. http://ensanut.insp.mx/ ensanut2016/descarga_bases.php\#.WVplaIWcEyE （accessed June 2017).

16. Perez Ferrer C (2015) Socioeconomic inequalities in obesity among Mexican adults 1988-2012. PhD Thesis, University College London.

17. Gutierrez JP, Rivera J, Shamah-Levy T et al. (2012) Encuesta Nacional de Salud Nutricion 2012: Resultados Nacionales. Cuernavaca, Mexico: Instituto Nacional de Salud Publica.

18. Filmer D \& Pritchett LH (2001) Estimating wealth effects without expenditure data - or tears: an application to educational enrollments in states of India. Demography $\mathbf{3 8}$, $115-132$.

19. Howe LD, Hargreaves JR \& Huttly SR (2008) Issues in the construction of wealth indices for the measurement of socio-economic position in low-income countries. Emerg Themes Epidemiol 5, 3.

20. Colchero MA \& Sosa-Rubi SG (2012) Heterogeneity of income and lifestyle determinants of body weight among adult women in Mexico, 2006. Soc Sci Med 75, 120-128.

21. Barros AJ \& Hirakata VN (2003) Alternatives for logistic regression in cross-sectional studies: an empirical comparison of models that directly estimate the prevalence ratio. BMC Med Res Methodol 3, 21.

22. Khang YH, Yun SC \& Lynch JW (2008) Monitoring trends in socioeconomic health inequalities: it matters how you measure. BMC Public Health 8, 66.

23. Neufeld LM, Hernandez-Cordero S, Fernald LC et al. (2008) Overweight and obesity doubled over a 6-year period in young women living in poverty in Mexico. Obesity (Silver Spring) 16, 714-717.

24. Fernald LC (2007) Socio-economic status and body mass index in low-income Mexican adults. Soc Sci Med 64, 2030-2042.

25. Galobardes B, Shaw M, Lawlor DA et al. (2006) Indicators of socioeconomic position (part 1). J Epidemiol Community Health 60, 7-12.

26. Morrison K (1995) Marx, Durkheim, Weber: Formations of Modern Social Thought. London: SAGE Publications Ltd. 
27. Drewnowski A \& Specter SE (2004) Poverty and obesity: the role of energy density and energy costs. Am J Clin Nutr 79, 6-16.

28. Roskam AJ, Kunst AE, Van Oyen H et al. (2010) Comparative appraisal of educational inequalities in overweight and obesity among adults in 19 European countries. Int J Epidemiol 39, 392-404.

29. Marmot M, Friel S, Bell R et al. (2008) Closing the gap in a generation: health equity through action on the social determinants of health. Lancet 372, 1661-1669.
30. Howe LD, Hargreaves JR, Gabrysch S et al. (2009) Is the wealth index a proxy for consumption expenditure? A systematic review. J Epidemiol Community Health 63, 871-877.

31. Ministry of Health (2010) Acuerdo nacional para la salud alimentaria: Estrategia contra el sobrepeso y la obesidad. http:// activate.gob.mx/Documentos/ACUERDO\%20NACIONAL\%20 POR\%20LA\%20SALUD\%20ALIMENTARIA.pdf (accessed December 2014). 